\title{
The Visibility of Disabilities within Pharmacy Program Recruitment Material
}

\author{
Farhat Naz Hussain, MPharm ${ }^{1}$; Alesha Smith, BSc, MSc, PhD'; Kyle John Wilby, BSP, ACPR, PharmD, PhD
}

${ }^{1}$ College of Pharmacy, QU Health, Qatar University; ${ }^{2}$ School of Pharmacy, University of Otago

\begin{abstract}
Background: Targeted recruitment of students with disabilities is a novel area in pharmacy education and may help to attract qualified students in light of decreasing applicant numbers. The aim of this study was to explore the visibility of disabilities within online recruitment material for pharmacy programs and to determine the location of targeted information available to prospective students with disabilities.

Methods: The top 50 ranked programs offering a professional pharmacy degree under the Pharmacy and Pharmacology QS subject rankings were identified and included if recruitment material was published in English. Online recruitment material was revie wed for presence of persons with disabilities in photos, presence or description of persons with disabilities in videos, information specific to disabilities on the program website (e.g. technical standards), and information specific to disabilities on the university website (if not located on the program website).

Results: A total of 41 international program websites met the inclusion criteria. No programs included pictures or videos featuring persons with disabilities. A total of 18 (44\%) of programs had disability information on the program website and an additional 18 (44\%) of programs included information on the university website. There were 5 (12\%) of programs that did not include any information about disabilities on the program or university website.

Conclusion: Recruitment material for pharmacy degree programs should be current, inclusive, and reflective of student populations eligible to be admitted. This study found a distinct underrepresentation of students with disabilities and information pertaining to disabilities within recruitment material for a sample of international pharmacy programs.
\end{abstract}

Keywords: disability, pharmacy education, recruitment, equity, diversity

\section{INTRODUCTION}

Recruitment of students is a challenge faced by pharmacy schools worldwide, where many report a decline in the number of applicants over recent years. ${ }^{1-3}$ For example, from Fall 20102017 there was a 35\% reduction in applicants to Doctor of Pharmacy programs observed in the United States of America (USA). ${ }^{3}$ Fewer applicants may mean decreased revenue, less diverse applicant pool, and reduction in the academic strength of students admitted. Pavuluri et al. suggest that strategic approaches to addressing declining enrollment should be the priority of the academy moving forward. ${ }^{4}$ To date, however, there is limited information on how pharmacy schools are working to draw interest to professional pharmacy programs. ${ }^{1}$ One approach that appears to be largely unexplored is the recruitment and targeting of special populations, such as those students who present with pre-existing disabilities. It is wellestablished that persons with disabilities consume disproportionately more healthcare resources than nondisabled persons, but generally experience poorer outcomes. ${ }^{5}$ Having more front-line pharmacists with a visible disability may help bridge the cultural divide between health care services and disabled patients and ultimately promote more accessible services and patient outcomes for this population.

Corresponding author: Kyle John Wilby, BSP, ACPR, PharmD, PhD; School of Pharmacy, University of Otago

PO Box 56, Dunedin, New Zealand 9054

Phone: +64 34797325

Email: kyle.wilby@otago.ac.nz
The World Health Organization classifies 'disability' into three categories; 6

1. Impairment - a problem in body function such as loss of a limb, memory loss, or vision loss,

2. Activity limitations - difficulty in executing a task or action such as seeing, hearing or walking,

3. Participation restriction - issues with involvement in life situations, such as working and engaging in social and recreational activities.

Likely a result of changing legislation and widening participation initiatives across many countries, the number of students with disabilities applying and attending higher education has greatly increased and these students are to be granted equal access to all aspects of education. ${ }^{7}$ This is corroborated in the USA by the Rehabilitation Act of 1973, which protects children and adults with disability from discrimination in education, workplace and other settings that receive federal financial assistance. ${ }^{8}$ The Accreditation Council for Pharmacy Education (ACPE) state in their accreditation standards that the respective college must provide appropriate accommodation to students who have documented disabilities as deemed reasonable by the University disability or student support office. ${ }^{9}$ Programs are also moving forward with other strategies, such as universal design for learning (UDL). ${ }^{10}$ UDL allows variations in teaching and learning to provide material that is accessible for all students, including those with disabilities. This removes any discrimination students may experience when requiring specific accommodation for educational material. Although a newer concept, program redesign may offer a more affordable 
approach for managing disabilities and creating an inclusive learning environment.

Pharmacy programs (especially within the United States and Canada) are publishing technical standards, which are the skills and abilities required of graduates to function as health professionals. $^{11}$ These standards may be present during admissions procedures, but do not appear to inform targeted recruitment of students with disabilities who meet technical requirements. Research surrounding technical standards is limited and primarily focuses on their availability, as well as legal implications. ${ }^{11,12}$ Other literature explores learning disabilities within pharmacy, ${ }^{8,13}$ medicine ${ }^{7,14}$ and nursing ${ }^{15}$ programs relating to experiential education, accommodation and assessment methods. The idea of targeted recruitment, or perhaps better-informed recruitment, of these students is novel. Despite some situations where the presence of a certain disability may preclude success in the program (as outlined in the technical standards), the majority of student disabilities can likely be accommodated and these students may, in fact, be very successful academically. Despite these considerations, it appears disabled persons have been historically academically disadvantaged, as reports have shown lower rates of postsecondary school qualifications, including bachelor degrees. ${ }^{16}$

Given the increased visibility of disabilities in society and promotion of educational and occupational equity, the aim of this study was to explore the visibility of disabilities within online recruitment material for international pharmacy programs and determine the location of targeted information available to prospective students with disabilities.

\section{METHODS}

This study extracted data from online recruitment material freely available from pharmacy program websites. A digital search was conducted using the 'QS Top Universities' website and QS world university rankings by subject in 2019. ${ }^{17}$ The search was limited to programs within the 'Pharmacy and Pharmacology' subject list. The top 50 ranked universities that offered a professional pharmacy degree (e.g. BSc (Pharm), BPharm, PharmD) and had recruitment material published in English were included in the study. Those universities that do not offer a professional pharmacy program or did not have recruitment material published in English were excluded.

Website information was reviewed for presence of information about disabilities as described according to the categories below. All types of disability-related information were reviewed, including general descriptions and contact information, specific information about accommodations, and professional technical standards. Data extraction was completed using a tool developed in Microsoft Excel (Microsoft Corporation, Redmond, WA) that recorded institution rank, name, pictures present on homepage or degree page $(\mathrm{Y} / \mathrm{N})$, visible disability present in pictures $(\mathrm{Y} / \mathrm{N})$, videos present on homepage or degree page $(\mathrm{Y} / \mathrm{N})$, disability (visible or described) present in videos $(\mathrm{Y} / \mathrm{N})$, disability information present directly on the program website $(\mathrm{Y} / \mathrm{N})$, or links to information on a separate university website if not on the program website $(\mathrm{Y} / \mathrm{N})$. Presence of images or videos of persons wearing glasses were not considered a disability. For each institution, the pharmacy website (pages included the home page, about us, program information, information for students, etc.) was scanned for the above identifiers and recorded. Only pictures and videos targeting student recruitment were reviewed. If there was no information recorded on the pharmacy homepage, the university website was searched for information using both manual screening and search functions. Any available information for prospective or current students with disabilities was added to the excel sheet through a web link. This process was continued until data were extracted for all included programs. Extraction was completed by one investigator $(\mathrm{FH})$ and validated by a second investigator (AS or KW) for each program.

All data was uploaded into Statistical Package for the Social Sciences v. 25 (International Business Machines (IBM) Corporation, Armonk, New York) for analysis. Descriptive statistics were used to summarize each criterion assessed. Institutions were further classified by region (North America, Europe, Australia/New Zealand, and Asia) and descriptive statistics were used to summarize each region's findings.

\section{RESULTS}

Of the top 50 pharmacy schools ranked, 41 met the inclusion criteria (82\%). Five schools were excluded based on language and four schools were excluded for not having a professional pharmacy program. Results were summarized and categorized by region (Table 1). Of all programs displaying photos or videos on recruitment websites, none included students with recognizable disabilities or described any information in promotional videos. A total of 18 programs (44\%) included information for students with disabilities on the programspecific website. Two (5\%) included professional technical standards. Aside from these two programs, this information largely consisted of generic statements, links to student support, or contact information. Eighteen schools (44\%) had information for students with disabilities on the university website. No information for students with disabilities could be found for the remaining five (12\%) programs/institutions. The type of information provided was highly variable across programs/institutions: links to student support, nondiscrimination policies, and admission requirements (including specific physical requirements required to undertake the program), were examples. In terms of regional differences, all programs in North America, Europe, and Oceania had disability information on either the pharmacy program webpage or the university/institution webpage. A total of three (37.5\%) programs in Asia provided this information. 


\section{DISCUSSION}

Aims of this study were to explore the visibility of disabilities within online recruitment material for international pharmacy programs and to determine the location of targeted information available to prospective students with disabilities. Results show information is provided to students with disabilities, either directly from the program (44\%) or through a university website (44\%). Almost all information extracted was general in nature. Results also show a distinct lack of visibility of students with disabilities within recruitment and promotional pictures and videos ( $0 \%$, for both). These findings have implications for student recruitment and pharmacy programs' commitment to equity and diversity.

The absence of photos or videos showing or describing students with disabilities may send a message that programs are not interested in proactively recruiting these students. In recent years, programs have greatly increased diversity in recruitment material pertaining to factors such as race, gender, and age (even to the point of overrepresentation) ${ }^{18}$ yet the results from this study suggest the opposite for disabilities. There may be many reasons for this finding (intentional vs. unintentional exclusion), but with an increasing known prevalence of students with disabilities in health professional programs, ${ }^{19}$ recruitment material should be revisited to determine whether or not it adequately reflects student populations eligible for pharmacy, including those with disabilities. Online videos could also provide verbal information about admission requirements and provisions available for students with disabilities. Doing so may not only improve a program's commitment to equity and diversity, but could also attract qualified individuals who may not otherwise know that studying pharmacy is a potential option for them.

A positive finding of this study was that information about disabilities could be found for $88 \%$ of programs searched. That being said, the majority of programs (56\%) only included information at the university-level or did not include any information that could be found. This is an important finding, as general information provided on a university website is not targeted to the program of interest. A student interested in pursuing pharmacy may not have a clear understanding of their disability's effect on their performance. In addition, university websites may not provide resources or contacts to make further inquiries. Programs that explicitly address the notion of disabilities directly within recruitment material and on the program's website may be more appealing to qualified students. It may therefore be ideal to publish professional technical standards on websites, in order to ensure students are well-informed of requirements post-graduation. In addition to technical standards, it may be helpful to post a list of accommodations that could be provided to students with disabilities for program-related activities. Information should include specifications about physical access, as well as learning support available (e.g. tutoring, study groups, recorded lectures)..$^{20}$ This information may help students make informed choices about whether or not a program (or profession) is a good choice for their abilities and needs. Information should also include links or contacts for students to obtain further information.

The findings of this study provide directions for future initiatives and research. As the roles and responsibilities of pharmacists are changing worldwide, collective regional or global efforts should be made to review and finalize professional technical standards. ${ }^{11,12}$ Although technical standards may differ across countries and job contexts, establishing a baseline of standards may inform suitable types of accommodations for students across both on-campus and off-campus (e.g. experiential training) settings. ${ }^{8,13}$ Future research should also focus on whether or not increasing the visibility of both visible and invisible disabilities within recruitment material (e.g. photos, videos, anecdotal accounts from enrolled students) has impact on student interest and admissions to pharmacy programs. A more detailed analysis of inter-regional/country differences is also warranted.

This study has limitations that should be addressed. First, many disabilities are not visible, and thus cannot be seen within recruitment pictures or videos. It should be noted, however, that no description of students with disabilities was recorded within this material. Secondly, only 41 programs were included based on the inclusion and exclusion criteria; results may not be generalizable across all pharmacy programs. The consistent nature of the findings, however, likely suggest that this may be a relevant issue for most pharmacy programs worldwide. Despite the benefits of focusing on students with disability and recruitment, institutions should aim to self-reflect and strive to ensure they have the capacity to serve these students once admitted to provide optimal educational requirements. Finally, technical standards may be embedded within admission material but not visible on program websites aimed at student recruitment. Therefore, it is possible that these documents were not captured by the methods employed, but also suggests visibility of these documents may be lacking.

\section{CONCLUSION}

Recruitment material for pharmacy degree programs should be current, inclusive, and reflective of student populations eligible to be admitted. This study found a distinct underrepresentation of students with disabilities and although information about disabilities was provided on websites, it was typically general and not program-specific. Findings support the notion that programs need to exercise greater efforts to support recruitment of students with disabilities by including visual, audio, or written information within recruitment material and by outlining program-specific technical standards and accommodations available for students to make informed program choice selections.

\section{Funding/Support: None \\ Conflicts of Interest: None}




\section{REFERENCES}

1. Myers TL, DeHart RM, Dunn EB, Gardner SF. A summer pharmacy camp for high school students as a pharmacy student recruitment tool. Am J Pharm Educ. 2012;76(4): Article 60. doi:10.5688/ajpe76460

2. Curtis SD, Felid C, Buring SM. A task force on recruitment, admissions, and retention to improve pharmacy college admissions outcomes. Am J Pharm Educ. 2019;83(9): Article 7307. doi:10.5688/ajpe7307

3. Choi AN, Flowers SK, Heldenbrand SD. Becoming more holistic: A literature review of nonacademic factors in the admissions process of colleges and schools of pharmacy and other health professions. Curr Pharm Teach Learn. 2018;10(10):1429-1437. doi:10.1016/j.cptl.2018.07.013

4. Pavuluri N, Aparasu RR, Boje KMK, et al. Consideration of aggressive and strategic approaches to address declining enrollment in US pharmacy schools. Am J Pharm Educ. 2019;83(6): Article 6959. doi:10.5688/ajpe6959

5. Smith WT, Roth JJ, Okoro O, Kimberlin C, Odedina FT. Disability in cultural competency pharmacy education. Am J Pharm Educ. 2011;75(2): Article 26.

6. Disabilities. World Health Organization. Accessed April 13, 2020. https://www.who.int/topics/disabilities/en/

7. Majumder MAA, Rahman S, D'Souza UJA, Elbeheri G, Bin Abdulrahman K, Huq MM. Supporting medical students with learning disabilities in Asian medical schools. Adv Med Educ Pract. 2010;1:31-39. doi:10.2147/AMEP.S13253

8. Afeli SA. Academic accommodation strategies for pharmacy students with learning disabilities: What else can be done? Curr Pharm Teach Learn. 2019;11(8):751-756. doi:10.1016/j.cptl.2019.04.001

9. PharmD Program Accreditation. Accreditation Council for Pharmacy Education. Accessed April 13, 2020. https://www.acpe-accredit.org/pharmd-programaccreditation/

10. Dalton EM, Lyner-Cleophas M, Ferguson BT, McKenzie J. Inclusion, universal design and universal design for learning in higher education: South Africa and the United States. Afr J Disabil. 2019;8:519. doi:10.4102/ajod.v8i0.519
11. Berry TM, Chichester CO, Lundquist LM, Sanoski CA, Woodward DA, Worley MM, Early JL. Professional technical standards in colleges and schools of pharmacy. Am J Pharm Educ. 2011;75(3): Article 50. doi:10.5688/ajpe75350

12. Lipton DA. A review of legal decisions relevant to technical standards used in pharmacy school admissions. Am J Pharm Educ. 2017;81(2): Article 37. doi:10.5688/ajpe81237

13. Vos S, Kooyman C, Feudo D, Goliak KL, Kieser M, Legg $J$, et al. When experiential education intersects with learning disabilities. Am J Pharm Educ. 2019;83(8): Article 7468. doi:10.5688/ajpe7468

14. Javaeed A. Learning disabilities and medical students. MedEdPublish. 2018;7(3):4. doi:10.15694/mep.2018.0000142.1

15. Watson PG. Nursing students with disabilities: a survey of baccalaureate nursing programs. J Prof Nurs. 1995;11(3):147-153. doi:10.1016/S87557223(95)80113-8

16. Klijs B, Nusselder WJ, Looman CW, Mackenbach JP. Educational disparities in the burden of disability: contributions of disease prevalence and disabling impact. Am J Public Health. 2014;104(8):e141-e148. doi:10.2105/AJPH.2014.301924

17. Pharmacy \& Pharmacology. QS World University Rankings. Accessed April 13, 2020. https://www.topuniversities.com/universityrankings/university-subject-rankings/2020/pharmacypharmacology

18. Pippert TD, Essenburg LJ, Matchett EJ. We've got minorities, yes we do: visual representations of racial and ethnic diversity in college recruitment materials. J Market High Educ. 2013;23(3):258-282. doi:10.1080/08841241.2013.867920

19. Meeks LM, Herzer KR. Prevalence of self-disclosed disability among medical students in US allopathic medical schools. JAMA. 2016;316(21):2271-2272. doi:10.1001/jama.2016.10544

20. Earle D. Disabled people and tertiary education: an analysis of the 2013 disability survey. Ministry of Education. Accessed April 13, 2020. https://www.educationcounts.govt.nz/publications/8 0898/disabled-people-and-tertiary-education 
Table 1. Presence of disability information on pharmacy program or institutional websites

\begin{tabular}{|c|c|c|c|}
\hline $\begin{array}{l}\text { Number of universities } \\
\text { by region }\end{array}$ & $\begin{array}{l}\text { Disability in pictures or } \\
\text { videos } \\
\mathrm{N}(\%)\end{array}$ & $\begin{array}{l}\text { Disability information on } \\
\text { pharmacy page } \\
\mathrm{N}(\%)\end{array}$ & $\begin{array}{l}\text { Disability information on } \\
\text { university page } \\
\text { (if not located on program- } \\
\text { specific pages) } \\
\mathrm{N}(\%) \\
\end{array}$ \\
\hline \multicolumn{4}{|l|}{ North America } \\
\hline Canada $(n=4)$ & 0 & $2(50)$ & $2(50)$ \\
\hline USA $(n=13)$ & 0 & $11(85)$ & $2(15)$ \\
\hline \multicolumn{4}{|l|}{ Europe } \\
\hline UK $(n=7)$ & 0 & $2(29)$ & $5(71)$ \\
\hline Italy ( $n=2)$ & 0 & $1(50)$ & $1(50)$ \\
\hline Germany $(n=1)$ & 0 & 0 & $1(100)$ \\
\hline Spain $(n=1)$ & 0 & 0 & $1(100)$ \\
\hline Belgium ( $n=1$ ) & 0 & 0 & $1(100)$ \\
\hline \multicolumn{4}{|l|}{ Oceania } \\
\hline Australia $(n=3)$ & 0 & $2(67)$ & $1(33)$ \\
\hline New Zealand $(n=1)$ & 0 & 0 & $1(100)$ \\
\hline \multicolumn{4}{|l|}{ Asia } \\
\hline Singapore $(n=1)$ & 0 & 0 & 0 \\
\hline South Korea $(n=3)$ & 0 & 0 & $2(67)$ \\
\hline Hong Kong ( $n=1)$ & 0 & 0 & 0 \\
\hline China $(n=3)$ & 0 & 0 & $1(33)$ \\
\hline
\end{tabular}

